\title{
Penetration of coastal waters into the Eastern Mediterranean Sea using the SeaWiFS data
}

\author{
Pénétration des eaux côtières en zone océanique de Méditerranée \\ orientale à partir de données SeaWiFS
}

\author{
Guenrik Karabashev*, Marina Evdoshenko, Sergei Sheberstov \\ P.P. Shirshov Institute of Oceanology, Russian Academy of Sciences, 36 Nakhimovsky prospekt, 117997 Moscow, Russia
}

\begin{abstract}
Offward transport of surface coastal waters was studied in the Eastern Mediterranean from $31^{\circ}$ to $37^{\circ} \mathrm{N}$ between $31^{\circ}$ to $36^{\circ} \mathrm{E}$ using cluster analysis of water-leaving radiance spectra from SeaWiFS color scanner imagery for spring-summer period of 1998. Some types of spectra were found to be characteristic of products of mixing of coastal and offshore waters and served as a quasiconservative tracer of water transport. Three sectors of the eastern coastal zone supplied colored and suspended matter into the open sea areas as occasional pulse discharges of 3-5 week periodicity. The Haifa sector was the most powerful source of such matter producing traceable separate radiance inhomogeneities as far as $200 \mathrm{~km}$ west of Haifa. It appears that the discharges were triggered when a set of specific conditions took place and that evolution and life time of discharged waters depended on currents and horizontal mixing. Advantages of cluster approach to imagery analysis are briefly discussed. () 2002 Ifremer/CNRS/IRD/Éditions scientifiques et médicales Elsevier SAS. All rights reserved.
\end{abstract}

\section{Résumé}

L'apport d'eaux côtières à la zone océanique de Méditerranée orientale a été étudié par l'analyse des spectres d'irradiance ascendante provenant de SeaWiFS pour la période comprise entre avril et août 1998. Quelques types de spectres caractérisent le mélange des eaux côtières avec celles du large et peuvent être utilisés comme indicateurs preque « conservatifs » du transport des eaux. Trois secteurs côtiers fournissent des substances colorées et des matières en suspension à l'océan ouvert, sous forme d'impulsions de périodicité comprise entre trois et cinq semaines. Le secteur de Haïfa constitue la source majeure, ce qui entraîne des hétérogénéités isolées jusqu'à 200 km de Haïfa. Apparemment, ces apports dépendent de conditions favorables et la durée de vie des eaux côtières au large dépend des courants et du mélange horizontal. Les avantages d'une approche basée sur la classification objective des spectres d'images satellitales sont discutés. (C) 2002 Ifremer/CNRS/IRD/Éditions scientifiques et médicales Elsevier SAS. Tous droits réservés.

Keywords: Radiance distribution; Eastern Mediterranean; SeaWiFS

Mots clés: Distribution des irradiances; Méditerranée orientale; SeaWiFS

\section{Introduction}

The oceanological processes in the surface layer of the ocean were successfully studied from the normalized waterleaving radiance $L_{W N}$ from the CZCS data Barale et al 1986; Mitchelson-Jacoh, 1993. The CZCS scanner made

\footnotetext{
* Corresponding author.

E-mail address: genskara@mtu-net.ru (G. Karabashev).
}

possible to observe coastal upwellings, river plumes, and other events influencing the fate of the light absorbing and scattering substances in the sea. $L_{W N}(\lambda)$ is proportional to the ratio

$$
L_{W N}(\lambda) \sim b_{b}(\lambda) / a(\lambda)
$$

where $a(\lambda)$ and $b_{b}(\lambda)$ are coefficients of light absorption and backscattering and $\lambda$ is the wavelength of light. These coefficients directly depend on concentrations of colored 
and suspended matter, respectively, which determines the value of observations of $L_{W N}$. They have become even more attractive after advent of the SeaWiFS color scanner in late 1997 because of its advanced hardware and flight specifications.

The goals of the present study are (1) to reveal water exchanges between the coastal and open areas of the Eastern Mediterranean during the spring-summer period using distributions of $L_{W N}$; (2) to obtain a notion of their features and relations to the environment factors; (3) to get more specific knowledge of feasibility of studying the oceanological processes from the radiance distributions.

Among the SeaWiFS products, only normalized radiances $L_{W N}(412), L_{W N}(443), L_{W N}(490), L_{W N}(510)$, and $L_{W N}(555)$ are used in the present study. Diffuse attenuation coefficient $K(490)$ and pigment concentration $C h l$ are also available as products of the same level as $L_{W N}(\lambda)$ and inevitably effected by water exchange processes. However, $K(490)$ and $C h l$ are calculated from $L_{W N}$ using regressions based on the notions of Case 1 (open ocean) and Case 2 (shelf and coastal areas) waters which are assumed to be strongly different in mechanisms of formation of the waterleaving radiance (Gordon et al, 1988; Morel, 1988) The present study is aimed at transition processes and areas where it is difficult to apply these notions and to guarantee the reliability of estimates of calculated quantities. In contrast, the spectral range of the SeaWiFS scanner allows us to use both magnitude and spectral course of $L_{W N}$ as qualitative diagnostic indicators of waters due to analytical dependence (1). The spectral course of large particles backscattering is nonselective while fine particle backscatter rapidly grows with diminishing wavelength. The large particles in sea water rapidly decrease in number with distance from their sources, be it an algal bloom, surf zone or river mouth. Hence, the shape of $b_{b}$ in (1) is indicative of long-range action of such sources. In the SeaWiFS's spectral region of $412-555 \mathrm{~nm}$, light absorption by sea water exponentially grows towards shorter wavelength due to the colored dissolved organic matter (CDOM) and can be influenced by contaminants, phytoplankton pigments and other colored substances having specific absorption maxima (the blue absorption band of chlorophyll, for instance). Their sources also gravitate towards coastal areas and local disturbances in the open sea which contributes to variability in $L_{W N}(\lambda)$ within transition zones. The factors influencing $b_{h}$ and $a$ are well understood at a qualitative level Jerlov 1976] but complexity of the matter prevents from quantifying their influence and to assess the prospects of diagnostics of surface layer processes from measured $L_{W N}(\lambda)$.

For the purpose to discriminate the changes in time and space, only 'instantaneous' images are used in the study. Finally, in order to minimize arbitrariness in data selection, to ensure compact presentation of the results, and to employ the spectra of image pixels as a multidimensional diagnostic signatures, we have resorted to the objective classification of spectra $L_{W N}(\lambda)$ of all pixels in images and most of attention was paid to analysis of distributions of spectral types but not to recorded radiances at individual wavelengths. This approach enabled to make use of all available information without neglecting fine but meaningful details.

The Eastern Mediterranean during spring-summer season was chosen as the aquatic area of fair weather and high surface water transparency (Ierlov, 1976) combined with local anthropogeneous impact on coastal zone.

\section{Materials and methods}

Level-2 GAC-data of $4.5 \mathrm{~km}$ resolution without averaging over time or space were used in the study. The data covering the region between $31^{\circ}$ and $37^{\circ} \mathrm{N}$ from $20^{\circ}$ to $37^{\circ} \mathrm{E}$ have been ordered from NASA for the period of April 1 to August 31, 1998. In total, 106 images have been obtained for the region relevant time interval of 09:30 to 10:30 GMT. Every image file contained geographical coordinates of meaningful pixels together with normalized radiances $L_{W N}(412), L_{W N}(443), L_{W N}(490), L_{W N}(510)$ and $L_{W N}(555)$. Preview of the materials has shown that the area between $31^{\circ}$ and $37^{\circ} \mathrm{N}$ from $31^{\circ}$ to $37^{\circ} \mathrm{E}$ better suited to study goals since there were coastal zone disturbances and local radiance contrasts in the open sea while occurrence of data gaps, due to cloudiness, sun glint, and the like, was about the same as outside the area. The latter was subdivided in the northern (NA) and the southern (SA) subareas with common boundary at $34^{\circ} \mathrm{N}$ because the subareas were distinct in oceanological conditions and features of radiance variability. A five-month series of images of acceptable quality was formed for each of the subareas (Table 1). The data of an image files were tabulated in such a way that table's row characterized a pixel by its coordinates and five spectral radiances.

Because of known difficulties there is no chances to find sea truth data concerning concentration and composition of colored and light scattering substances in sea water relevant to selected images. Therefore we are forced to restrict our considerations to published information on relevant factors in the Eastern Mediterranean and to distributions of sea surface temperature from NOAA satellites for the period and areas in question. Only 'night' temperature distributions are suitable in our case since 'day' patterns can be distorted by warming up of the sea surface. The data on the before-dawn sea surface temperature have been obtained as GAC-files. They were visually compared with $L_{W N}$ distributions.

Preview of radiance distributions over SA and NA at 412 and $555 \mathrm{~nm}$ has revealed that there was no clear evidence of penetration of coastal waters into the open sea in April and May. In all images of this period both radiances were almost evenly distributed over the areas excluding the coastal strip of lower $L_{W N}(412)$ and higher $L_{W N}(555)$. The strip was 40-70 km wide along the African coast and narrowed several times at higher latitudes. By the beginning of June 
Table 1

List of meaningful images for the northern (NA) and southern (SA) areas. (+) marks images used to compute the classes of radiance spectra. In total, 106 images covering both areas were available for the period of 09: 25 to 10: 30 from April to August

\begin{tabular}{|c|c|c|c|c|c|c|c|c|c|c|c|c|c|c|c|c|c|}
\hline 1 & Image & Date & Time & SA & NA & 1 & Image & Date & Time & SA & NA & 1 & Image & Date & Time & SA & NA \\
\hline 1 & 96 & 06.04 .98 & 09:47 & & & 13 & 158 & 07.06 .98 & $09: 52$ & + & & 24 & 200 & 19.07 .98 & $09: 55$ & + & \\
\hline 2 & 98 & 08.04 .98 & 09:38 & & & 14 & 167 & 16.06 .98 & 09:59 & + & + & 25 & 207 & 26.07 .98 & $10: 12$ & & \\
\hline 3 & 99 & 09.04 .98 & $10: 22$ & & & 15 & 174 & 23.06 .98 & $10: 16$ & + & + & 26 & 211 & 30.07 .98 & $09: 53$ & + & \\
\hline 4 & 101 & 11.04 .98 & $10: 13$ & & & 16 & 176 & 25.06 .98 & $10: 07$ & + & + & 27 & 220 & 08.08 .98 & $10: 01$ & + & + \\
\hline 5 & 103 & 13.04 .98 & $10: 03$ & & & 17 & 180 & 29.06 .98 & $09: 48$ & & & 28 & 226 & 14.08 .98 & 09:34 & & \\
\hline 6 & 110 & 20.04 .98 & $10: 20$ & & & 18 & 184 & 03.07 .98 & 09:30 & & & 29 & 229 & 17.08 .98 & $10: 10$ & + & + \\
\hline 7 & 114 & 24.04 .98 & 10:01 & & & 19 & 185 & 04.07 .98 & $10: 14$ & & & 30 & 231 & 19.08 .98 & $10: 00$ & + & + \\
\hline 8 & 121 & 01.05 .98 & $10: 17$ & & & 20 & 193 & 12.07 .98 & $09: 37$ & & & 31 & 233 & 21.08 .98 & 09:51 & & \\
\hline 9 & 136 & 16.05 .98 & $09: 56$ & & & 21 & 194 & 13.07 .98 & $10: 22$ & & & 32 & 235 & 23.08 .98 & $09: 42$ & + & + \\
\hline 10 & 145 & 25.05 .98 & $10: 03$ & & & 22 & 195 & 14.07 .98 & $09: 28$ & & & 33 & 237 & 25.08 .98 & $09: 33$ & & \\
\hline 11 & 154 & 03.06 .98 & $10: 11$ & + & & 23 & 196 & 15.07 .98 & $10: 13$ & + & + & 34 & 242 & 30.08 .98 & 09:59 & & \\
\hline 12 & 156 & 05.06 .98 & 10:01 & + & & & & & & & & & & & & & \\
\hline
\end{tabular}

the pattern became more complicated owing to coastal strip disturbances and separated offshore radiance extrema. In view of these circumstances and computational limitations, only part of the images have been chosen for clustering the radiance spectra (Table 1).

An initial data table of 60709 rows was composed of the chosen images, each row representing coordinates and five spectral radiances of a pixel. Using the radiances as clustering variables, we computed spectral classes applying the K-means method of cluster analysis (Aivazyan et al_, 1989) to the initial data table. After separating the spectra into classes and knowing cluster membership of an individual pixel's spectrum, we assigned the average spectrum (cluster center, or CC) of the respective class to each pixel and a symbol to each spectral class. This made possible to map the types of spectra in every image putting specific symbols at pixels latitude and longitude and using plots of CC as a key to interpret the maps. This procedure has been successfully employed for optical zoning of the ocean from the CZCS imagery (Karabashev ef al, 2000) and enables visualization of spectral-radiance structure of aquatic areas at spatial resolution to a pixel.

After some testing it was found that the number of classes $K=20$ is close to a reasonable trade-off of ease of use of the classification and a danger to miss some meaningful details because of insufficiently large K. Computations proceeded according to iteration algorithm aimed at formation of classes (clusters) the most distant from each other in the space of variables. The computations terminated when the increment of intercluster distances between CCs in the space of variables diminished below $10-15 \%$ of the shortest of them. The computed CCs were ordered in ascendance of $L_{W N}(412)$ so that the lower and higher classes should be typical of waters rich and poor in CDOM, respectively.

The spectra from images not included into the initial table were classed using minimum of the mean square deviation from computed CCs as a selection criterion. The latter is of the same meaning as the criteria of clusterization because it was performed in the Euclidean space of variables. Distributions of typical spectra, found from the
K-means technique and from the mean square deviation, turned out to be indistinguishable.

Major results of spectra clustering are presented in Table 2 and Fig. 1-4. In most of them the symbols of higher rank classes were changed for dots. This improved the readability of maps without diminishing their conclusive evidence.

\section{Results}

Statistical significance of the computed clusters is characterized by the $\mathrm{F}$ ratio of cluster variance to error variance (the variance not attributable to clusters). The value of $\mathrm{F}$, close to unity, indicates a variable of lesser usefulness for separating clusters. If such $\mathrm{F}$ estimates are inherent to all variables, they are unusable for identifying cluster membership of objects in question (in our case, these are the pixel's spectra). Five computed $\mathrm{F}$ ranged from $2 \cdot 10^{5}$ to $6 \cdot 10^{5}$ which is more than sufficient to believe that every variable was fairly useful for clustering and that the separated 20 spectral classes are of highest statistical significance.

The lower classes (1-4 in Fig. 1) gravitated towards the coastal zone as the higher ones (16-19 in Fig. 1) dominated the open sea. The spectra of type 20 were the most abundant in and around data gaps due to cloudiness. The most peculiar spectra of type 14 populated some sectors in the western African coastal zone in images 176 and 200. The spectra of type 6 belong to lower classes in rank and level of $L_{W N}(412)$ and, the latter alike, are present in the coastal zone excluding its African part west of $33^{\circ} 30^{\prime} \mathrm{E}$. At the same time they feature a broad maximum between 443 and $490 \mathrm{~nm}$ (Fig. 1) and rather often occur outside the coastal

Table 2

Population of classes of spectra $L_{W N}(\lambda)$

\begin{tabular}{|c|c|c|c|c|c|c|c|}
\hline Class & Population & Class & Population & Class & Population & Class & Population \\
\hline 1 & 129 & 6 & 1195 & 11 & 2985 & 16 & 1841 \\
\hline 2 & 239 & 7 & 982 & 12 & 1719 & 17 & 13946 \\
\hline 3 & 430 & 8 & 412 & 13 & 346 & 18 & 18139 \\
\hline 4 & 369 & 9 & 512 & 14 & 78 & 19 & 7989 \\
\hline 5 & 684 & 10 & 815 & 15 & 7011 & 20 & 888 \\
\hline
\end{tabular}




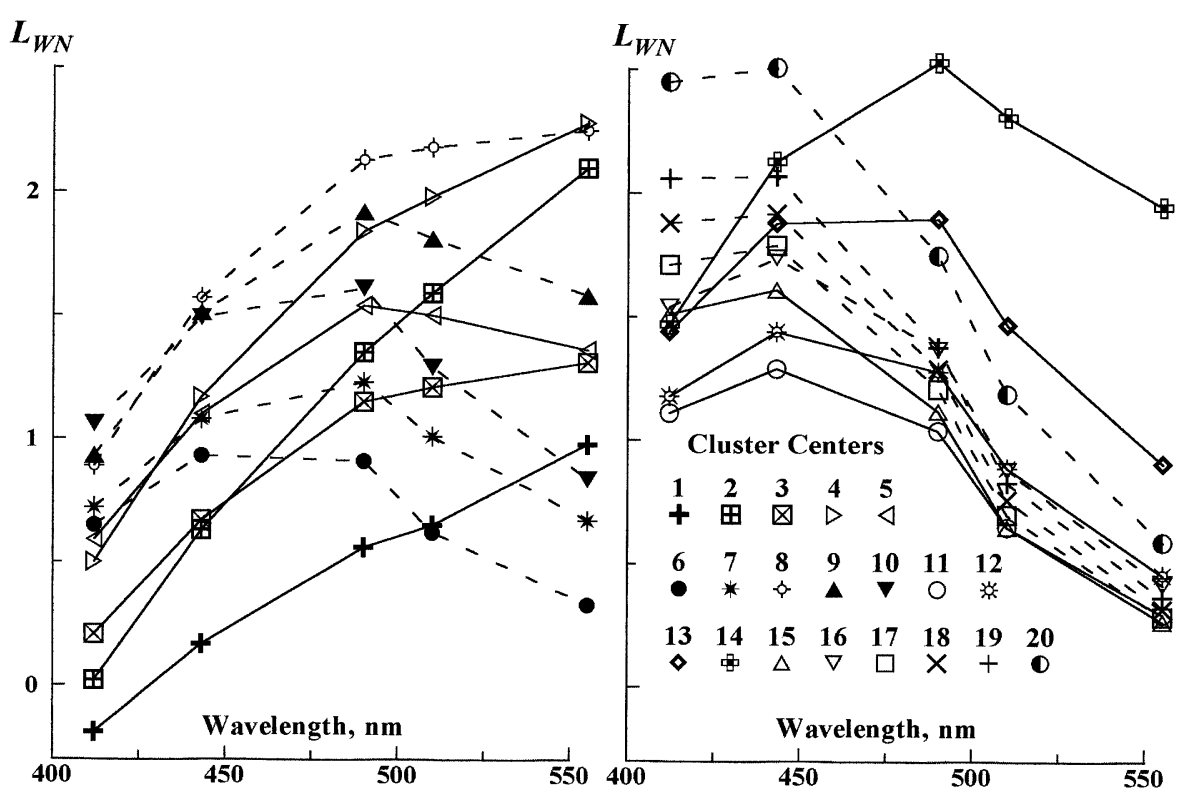

Fig. 1. Types of spectra $L_{W N}$ (cluster centers) computed from radiance spectra of 60709 pixels in a series of images for the south and north subareas.

zone which makes them similar to spectra of intermediate ranks 8-13 (Fig. 1).

In all of the images there are areas occupied by a single spectral class or by several classes of similar CCs. Some of the areas are time-independent in extension, position, and cluster membership of their pixels. For example, the spectra 9, 10, 13 were almost lacking in the eastern coastal zone from July to August but they permanently interfaced the offshore zone and the coastal strip west of $33^{\circ} 30^{\prime} \mathrm{E}$, occupied by spectra of low ranks (Fig. 2).

A 'tongue' of spectra 6 near Haifa (TH in Fig. 2) exemplifies the formation that is stationary in position but time-dependent in spectral membership. The tongue was discovered on July 13-15 (TH in Fig. 2 and 3), disappeared by July 30 (image 211) and reappeared on August 17-19. There were also cluster-homogeneous 'patches' of quasiconstant cluster composition but variable in space (images $156,158,174$ and others). Judging from patches $\mathrm{E}$ and $\mathrm{F}$ of spectra 11-12 (Fig. 2), such formations could live for many days and traveled tens of kilometers remaining almost unchanged in cluster composition. These patches were surrounded by spectra $18-19$ so that the ratio of $L_{W N}(\lambda)$ outside and inside a patch was as high as 2 (Fig. 1). Finally, the images 220, 229, 231 and 235 for NA (Fig. 4) show remarkable difference in behavior of neighbor formations: patch $\mathrm{H}$ disintegrated in several days while $\mathrm{G}$ survived during two weeks.

We failed to relate quasistationary or time-dependant spectrally-homogeneous formations to Sea surface temperature (SST) extrema in all images except 196 and 231 for SA featuring the tongues $\mathrm{TH}$ and TA of spectra 6 (Fig. 3).

\section{Discussion and conclusion}

The lower CCs in Fig. 1 feature negative or underestimated $L_{W N}$ in the violet-blue. These faulty negative $L_{W N}$ are caused by inadequacy of atmospheric correction McClain et al.,2000) but appear unimportant for our goals because the low rank CCs occur only within the coastal zone and are not involved in interpretation of the phenomena in question.

As a whole, the CCs in Fig. 1 agree in shape with published evidence on spectra of water-leaving radiance. There are no CCs whose $L_{W N}(443)$ lies below a line connecting $L_{W N}(412)$ and $L_{W N}(490)$. Such pattern could be indicative of the direct influence of chlorophyll on the shape of $L_{W N}(\lambda)$ since its absorption band peaks near $440 \mathrm{~nm}$. Sometimes the radiance minimum around this wavelength is really recorded in chlorophyll rich coastal and upwelling areas (Clarke et al, 1970. Siegel et al, 1994) so its absence in computed CCs tells that in our case chlorophyll contribution was negligible against backscatter and CDOM absorption and both factors have to play a key role in shaping $L_{W N}(\lambda)$ at least in areas unaffected by pollution.

The CCs 1-4 of positive spectral slope occur exclusively within the inner coastal zone (Fig. 2-4) and are attributable to the abundance of both CDOM and suspended matter. The first of them is the only conceivable cause of monotonous decrease of $L_{W N}(\lambda)$ towards shorter wavelengths while the second elevates $L_{W N}(555)$ above the level of the open sea waters (CCs 15-19) with decrease in CDOM absorption. Notice that low ranked CCs are particularly numerous in coastal zone of Nile delta and east of it between $32^{\circ}$ and $34^{\circ} \mathrm{E}$ (220 in Fig. 2). This observation justifies the dominance of CDOM and large particles in shaping low ranked 


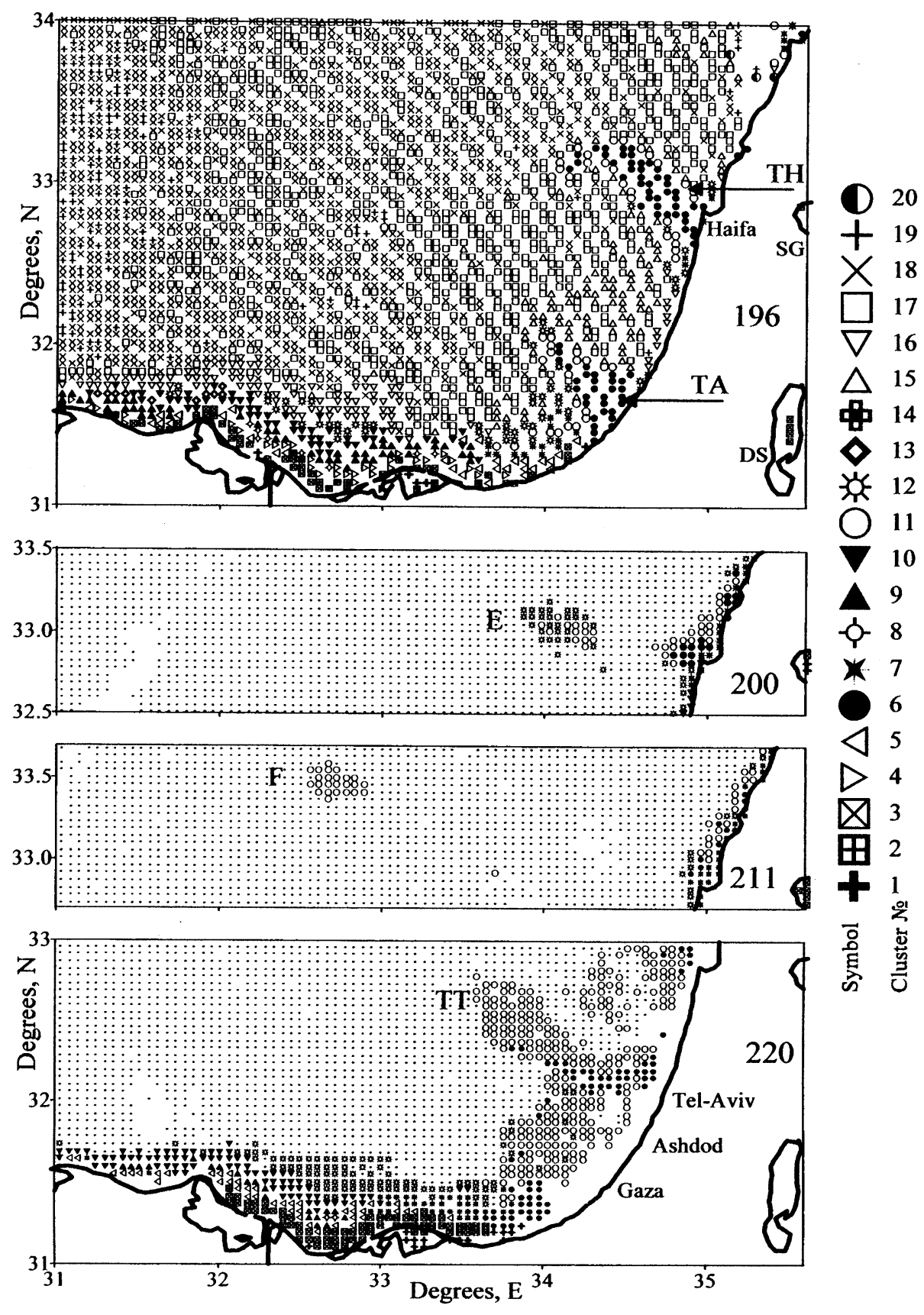

Fig. 2. Distribution of classes of radiance spectra over the southern aquatic area in images 196, 200, 211 and 220 (Table 1). Dots replace the symbols of spectra 13-19. SG and DS designate the Sea of Galilee and Dead Sea, respectively.

spectra because it is in agreement with well known facts: 1) the Nile river discharges waters rich in both substances; 2) these waters should be inevitably entrained by the eastward general circulation characteristic of the area.

The spectra 17-19 of the open sea are determined by selective backscatter of small particles, resulting in negative spectral slope, and slightly influenced by low content of CDOM at shorter wavelengths. Combined action of selective backscattering by particles of intermediate sizes and medium CDOM absorption may be responsible for middle rank spectra $6,7,9,10,11,12$ with diffused peak in the blue.

The area occupied by spectra 14 in image 176 from $3^{\circ}$ to $32^{\circ} \mathrm{E}$ extended along the $20 \mathrm{~m}$ isobath and bordered the transparent offshore waters of spectra 16-18. Therefore the spectra 14 were probably contributed by sun light diffuse reflection from the sea floor. The shape of absorption spectra of continental CDOM, hydrocarbon contaminants, indus 


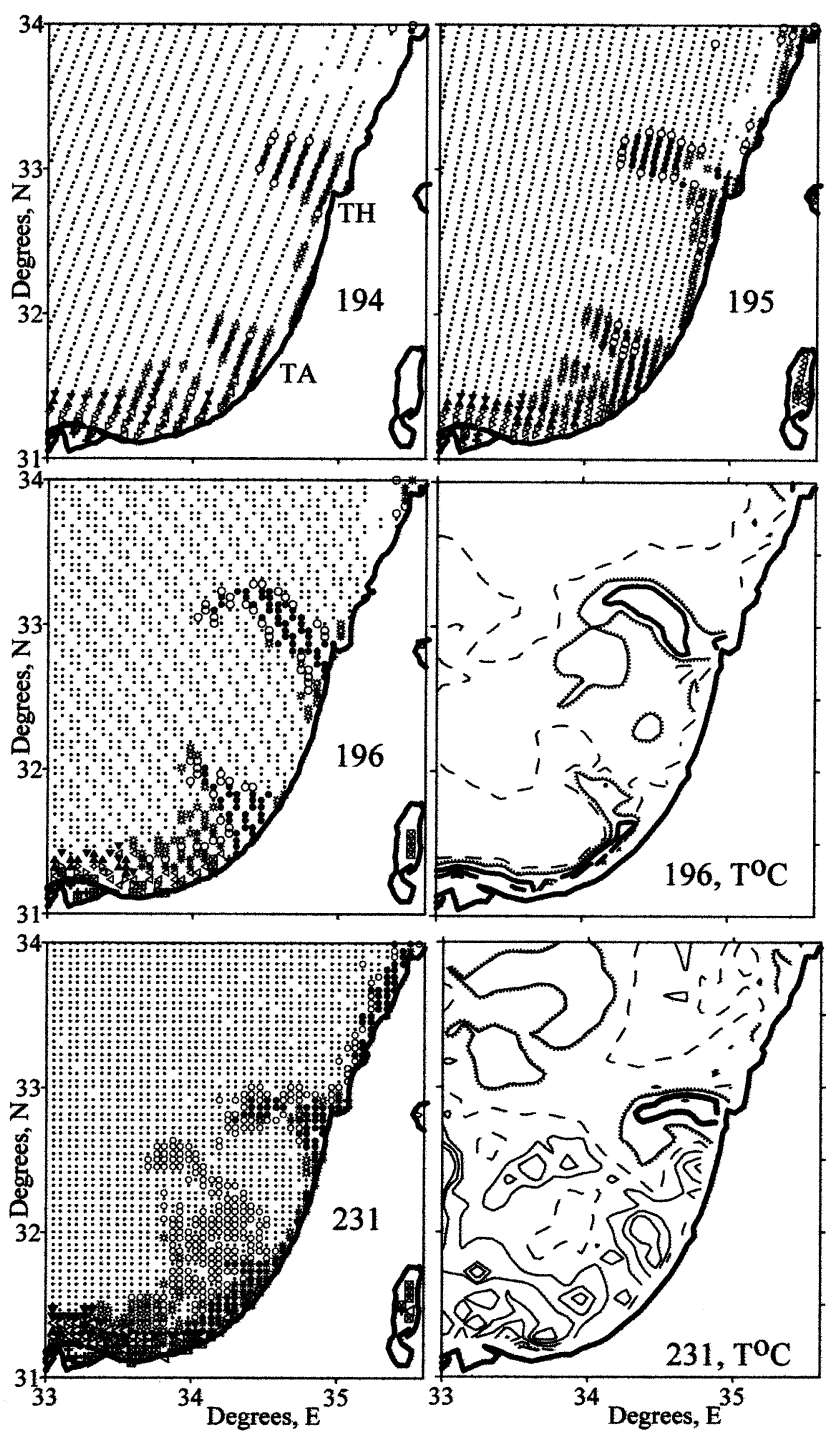

Fig. 3. The classes of radiance spectra and SST in the east of the SA in images 194, 195, 196, and 231. Dots replace the symbols of spectra 13-19. Thick, hachure, and broken contours are isotherms of $23.8^{\circ} \mathrm{C}, 23.5^{\circ} \mathrm{C}$, $23.2^{\circ} \mathrm{C}$ in image 196 and $25.5^{\circ} \mathrm{C}, 25.2^{\circ} \mathrm{C}, 24.9^{\circ} \mathrm{C}$ in image 231 .

trial and domestic wastes is such that it is difficult to discriminate them on the background of marine CDOM absorption using the filter photometer of the SeaWiFS class. Hence, it is not inconceivable that colored substances entering the sea with continental runoff or pollution also contributed coastal $L_{W N}(\lambda)$ of low and medium ranks (spectrum 6, for instance).

Striking similarity of the TH tongues and SST maxima (Fig. 3) provides evidence that the tongues appeared on July and August as a result of the off-shore horizontal transport of surface warmer waters, rich in colored substances and suspended particles. Judging from changes in shape of the TH in images 194, 195, and 196 (Fig. 3) and from the position of patch E (Fig. 2), this tongue could appear in the middle of the second week of July and disintegrated in 8-10 days. Penetration of the tongue by tens of kilometers into a province, occupied by spectra 17-19 and poor in CDOM and
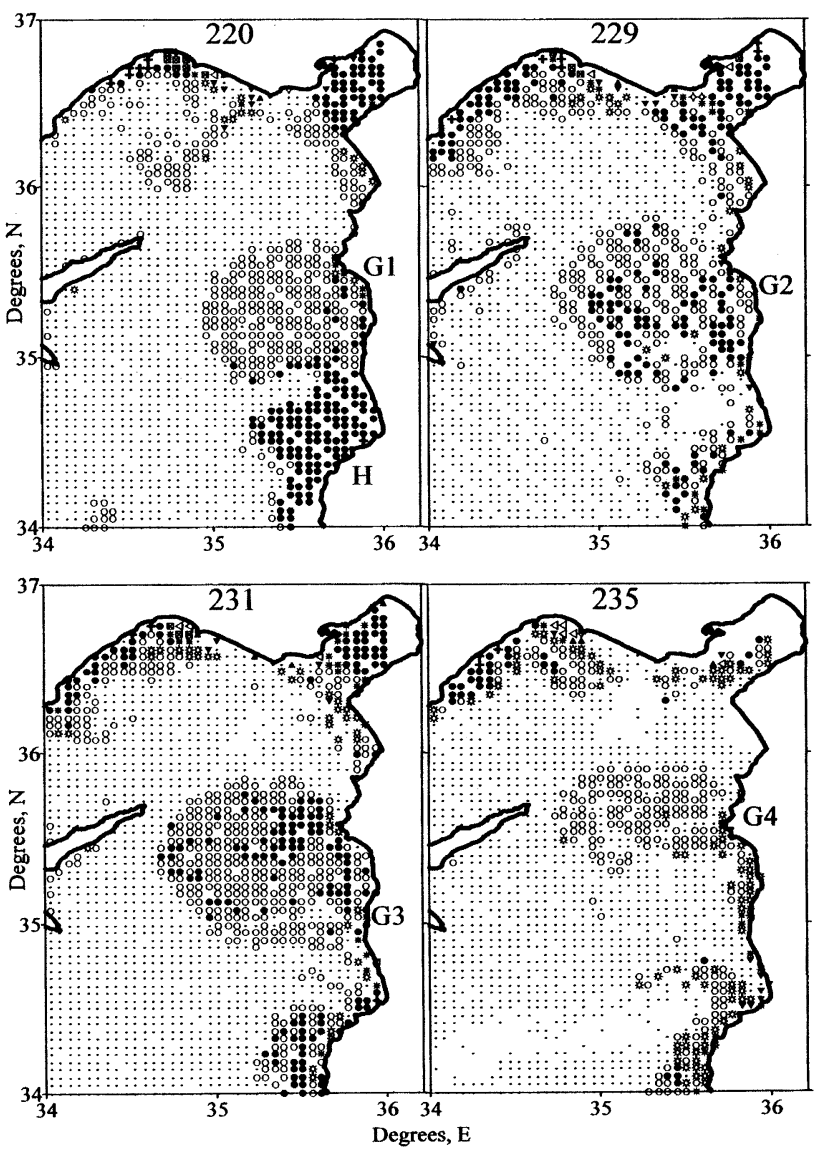

Fig. 4. The classes of radiance spectra in the northern aquatic area in images 220, 229, 231, and 235. Dots replace symbols of spectra 13-20.

particles, inevitably caused there strong horizontal gradients of their concentrations and subsequent smoothing of the gradients due to mixing of heterogeneous waters. The tongues TH and TA of spectra 6 in the SA images 194-196, 229 , and 231 were edged with spectra 11,12 and 15 . This fact and intermediate amplitude of these spectra testify that they are inherent to products of mixing of coastal and offshore waters and, therefore, can serve as indicators of penetration of colored and light scattering substances from coastal sources into the open sea. Really, in four days after July 15 the spectra 6 survived only near Haifa and a separate patch E of spectra 11-12 occurred instead of TH (196 and 200 in Fig. 2). Continuity of cluster composition of the tongue and patches, one and the same general direction of their migration into the open sea, and fairly rapid extinction of the TH tongue after July 15 allows us to consider these formations as successive manifestations of offward motion of a portion of water from the eastern coast. If this is true, this portion has passed $200 \mathrm{~km}$ following the mean course of $290^{\circ}-300^{\circ}$ during 15 days at average speed of $15 \mathrm{~cm} \mathrm{~s}^{-1}$ which is quite acceptable estimate for a surface current.

Separate patches of spectra 11-12 were also observed at Haifa latitude in images 156 and 158. The first one was latitudinally extended by about $70 \mathrm{~km}$ with its eastern tip at a distance of $35-40 \mathrm{~km}$ from the coast while the patch in 
image 158 was of meridianal extension. Their western fronts were spaced $45-50 \mathrm{~km}$ apart. Assuming that these patches represented successive manifestations of one and the same inhomogeneity, the latter was travelling at a speed of $17 \mathrm{~cm} \mathrm{~s}^{-1}$. Both speed estimates are quite typical of a surface current.

The patterns of greater diversity were characteristic of coastal zone from Tel-Aviv to Gaza. In addition to occasional tongues TA (196) and TT (220), poorly shaped patches of spectra 11-12 from time to time occupied both offshore and coastal zones protruding by tens of kilometers into the open sea (images 220 and 231 in Fig. 2 and 3 as well as images 233, 237 and 242)

In August, the patches of spectra 11-12 occurred in the east of NA amid the fields of spectra 16-18 (H, G1-G4 in Fig. 4). Similar inhomogeneities of lesser dimensions were earlier observed in images 167, 174, 176 and 196 in the south-east of NA. As follows from Fig. 4, their evolution may begin with appearance of a strong patch $\mathrm{H}$ of spectra 6 near Beyrut (several minutes south of latitude $34^{\circ} \mathrm{N}$ ). When moving northward, the patch mixes with transparent off shore waters, transforms into larger patches G1-G3 of spectra 11 and shrinks before vanishing (G4) about $100 \mathrm{~km}$ north of its birth place. Real scenario could involve coexistence of 'new' (H) and 'old' (G1) patches mutually mixing and jointly travelling northward. This explains cluster difference of patches $\mathrm{H}$ and $\mathrm{G} 1$, intermittence of spectra 6 and 11 in patches G2 and G3 and disappearance of spectra 6 from the 'eldest' patch G4.

Thus the surface layer of the open eastern Mediterranean was supplied by colored and light scattering substances from several sectors of the eastern coastal zone. Neither of the meaningful SA images from April to August provided evidence of surface water transport from the African coastal zone into the open sea.

Apparently, the development of Haifa tongues is caused by a long range supply mechanism. Their shape, size, and other features resemble properties of transversal filaments typical of several upwelling regions (Fedorov and Ginsburg. 1992) It was shown that these filaments feature density deficit due to lesser salinity in reference to surrounding waters. Owing to the deficit, the filament water allegedly slides over the underlying layer of 'normal' salinity. There are sources of warmer freshened waters at coastal part of the tongue $\mathrm{TH}$ (river Kishon and city wastes) so both salinity and temperature deficits of water density are quite probable in Haifa sector and facilitate generation of filament-like inhomogeneities. Same factors are probable near Beirut close to $34^{\circ} \mathrm{N}$. The density deficit at the coastal side of the tongues TA (196) and TT (220) can be due to wastes from Ashdod-Ghaza and Tel-Aviv sectors, respectively. A hypothesis of local density deficit of surface coastal waters as the first cause of their offshore migration agree well with the fact that all large tongues of spectra 6 were geographically bound to probable sources of warmer and/or freshened waters.
Transverse filaments are attributable also to interaction of an alongshore current and bottom topography Borzelliet al. 1999) There is an underwater elevation south of the port of Haifa as well as alongshore cyclonic circulation within the adjacent coastal zone. Conceivably occurrence and longer range of the TH tongue result from two mechanisms: offward sliding of lighter waters and offshore driving of surface water when coastal current hits southern slope of underwater elevation.

General cyclonic transport of surface waters along the African and Asian coasts is superimposed by gyres and eddies with orbital velocity of $20-40 \mathrm{~cm} \mathrm{~s}^{-1}$ and scales of about $100 \mathrm{~km}$ as well as by smaller eddies (Hecht et al. 1988: Krivosheya et al, 1999 , and others). Complexity of water motions exhibits, inter alia, in bending of the $\mathrm{TH}$ tongue and in southward shifting of its coastal base relative to the place of initial occurrence (194-196, 231 in Fig. 3). Most probably, horizontal eddy mixing dominated evolution of tongues TA and TT while patches in NA evolved due to both eddy mixing and cyclonic water transport.

The local freshening of coastal surface layer is a quasicontinuous process but coastal waters penetrated the open sea during summer season as occasional pulses but not as continuous outflows. The pulse nature of the penetration appears due to the triggering of the process by occasional combinations of favorable factors (rate of freshening, coastal currents and eddies, bottom topography, surface wind etc.). In summer 1998 they occurred in different sectors of the Asian coast ones in 3-5 weeks.

Visualization of distribution of spectral types has shown that the spectral classes are bound to specific oceanological conditions and that some of the classes are typical of products of mixing of coastal and offshore waters and can serve as quasiconservative indicators of presence of foreign colored and light scattering substances in the surface layer of the open sea. By virtue of their multidimensionality, typical radiance spectra are more specific to nature and origin of waters as compared to one-dimensional characteristics of the environment. For instance, the pixels of spectra 13-15 are indistinguishable at $412 \mathrm{~nm}$ while they are easy to discriminate from shape of these spectra (Fig. 1). On the contrary, the pixels of spectra 16-19 are quite distinguishable from spectral shape and level of $L_{W N}(412)$ but feature almost no differences in $L_{W N}(510)$ and $L_{W N}(555)$ (Fig. 1). All told, the separated classes turned out to be both statistically and contensively meaningful.

The use of objective classification of pixels'spectra for image analysis made possible to involve in analytical treatment all of the Level 2 data available from NASA for the required date, time, and locality and to discriminate fine but meaningful details. This advantage of cluster approach is of particular importance for analysis of real images where spectra of some pixels are spoiled by cloudiness, sun glint, or other known factors but not as strongly as to be flagged or masked during standard data processing. Distortions of this kind result in systematic and random inaccuracies if 
undetected by an end user that employs interpolation or evaluation of statistical moments.

Initial data set involved radiance spectra of waters of widely variable optical properties. The clustering results remained almost unchanged when obtained from different data subsamples using different software provided that $\mathrm{K}$, the method and metrics of classification were the same. Hence, revealed types of radiance spectra may be valid not only for the area and period of our studies. Nevertheless the computed classification is nothing more than a tool for solving specific problem. A universal objective classification of spectra of normalized water-leaving radiance will open new opportunities for users of satellite information on ocean color. For this purpose, it is necessary to develop special algorithm of cluster analysis enabling to extend the spectral classification as data accumulate and color scanners advance in spectral and spatial resolution.

\section{Acknowledgements}

Ocean color data used in this study were produced by the SeaWiFS Project at Goddard space flight center and obtained from the Goddard distributed active archive center under the auspices of the National aeronautics and space administration. The use of this data is in accord with the SeaWiFS research data use terms and conditions agreement. The authors are grateful to operators of the Rome station for initial data set.

\section{References}

Aivazyan, S.A., Buchstaber, V.M., Yenyukov, I.S., Meshalkin, L.D., 1989. Applied statistics. Classification and reduction of dimensionality, Finansy i statistica, Moscow. 607.

Barale, V., McClain, C.R., Malanotte-Rizzoli, P., 1986. Space and time variability of the surface color field in the northern Adriatic Sea. J. Geophys. Res. 91, 12957-12974.
Borzelli, G., Manzella, G., Marullo, S., Santoleri, R., 1999. Observations of coastal filaments in the Adriatic Sea. J. Mar. Syst. 20, 187-203.

Clarke, G.L., Ewing, G.C., Lorenzen, C.J., 1970. Spectra of the backscattered light from the sea obtained from aircraft as a measure of chlorophyll concentration. Science 167, 1119-1121.

Fedorov, K.N., Ginsburg, A.I., 1992. The near-surface Layer of the Ocean, VSP, Utrecht, The Netherlands. 259.

Gordon, H.R., Brown, O.B., Evans, R.H., Brown, J.W., Smith, R.C., Baker, K.S., Clark, D.K., 1988. A semianalytic radiance model of ocean color. J. Geoph. Res. 93, 10909-10924.

Hecht, A., Pinardi, N., Robinson, A.R., 1988. Currents, water masses, eddies and jets in the Mediterranean Levantine basin. J. Phys. Oceanogr. 18, 1320-1353.

Jerlov, N.G., 1976. Marine Optics. Elsevier, Amsterdam, pp. 231.

Karabashev, G.S., Kopelevich, O.V., Sheberstov, S.V., 2000. Objective classification of ocean regions taking into account seasonal changes, based on CZCS satellite color scanner data. Earth Obs. Rem. Sens. $16,57-72$.

Krivosheya, V.G., Ovchinnikov, I.M., Kos'yan, R.D., Titov, V.B., Moskalenko, L.V., Yakubenko, V.G., Abousamra, F., Aboucora, I., Bouras, K., 1999. The features of geostrophic circulation and currents in the Eastern Mediterranean between the Syrian Coast and Cyprus Island in winter and summer. In: Malanotte-Rizzoli, P., Eremeev, V.N (Eds.), The Eastern Mediterranean as a laboratory basin for the assessment of contrasting ecosystems. Kluwer Academic Publishers, Netherlands, pp. 113-126.

McClain, C.R., Barnes, R.A., Eplee Jr, R.E., Franz, B.A., Hsu, N.C., Patt, F.S., Pietras, C.M., Robinson, W.D., Schieber, B.D., Schmidt, G.M., Wang, M., Bailey, S.W., Werdell, P.J., 2000. SeaWiFS Postlaunch Calibration and Validation Analyses, Part 2. NASA Tech. Memo.2000-206892, Vol. 10. In: Hooker, S.B., Firestone, E.R (Eds.), NASA Goddard Space Flight Center, pp. 59.

Mitchelson-Jacob, G., 1993. Eddies in the Greenland Sea observed from infrared and visible satellite radiometry. Oceanol. Acta 16, 213-220.

Morel, A., 1988. Optical modeling of the upper ocean in relation to its biogeneous matter content (Case I water). J. Geoph. Res. 93, 10749-10768.

Siegel, H., Gerth, M., Beckert, M., 1994. The variation of optical properties in the Baltic Sea and algorithms for the application of remote sensing data. SPIE 2258. Ocean Optics XII, 894-905. 